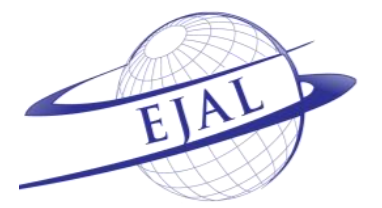

\title{
Variations in the Citation Use and Perceptions in Writing the Literature Review by EFL Postgraduates
}

\author{
Nayef Jomaa Jomaa a * (D), Siti Jamilah Bidin b $†$ (D) \\ a Karabuk University, Karabuk, Karabuk 78000, Turkey \\ ${ }_{b}$ Universiti Utara Malaysia, UUM Sintok, Kedah 06010, Malaysia
}

Received 20 February 2019 | Received in revised form 26 May 2019 | Accepted 14 October 2019

\begin{abstract}
APA Citation:
Jomaa, N. J. \& Bidin, S. J. (2019). Variations in the citation use and perceptions in writing the literature review by EFL postgraduates. Eurasian Journal of Applied Linguistics, 5(3), 441-460. Doi: 10.32601/ejal.651398
\end{abstract}

\begin{abstract}
Academically, citation is pivotal since it presents justifications for the arguments and a demonstration of the writer's position. Despite the increasing number of studies on citations, little knowledge has been reported regarding the citation use and practices of EFL students within the ESL context. Hence, the present study aimed at investigating the extent of variation in the citation practices in the literature review of $\mathrm{PhD}$ theses in Applied Linguistics and Information Technology. The study analysed the citations qualitatively focusing mainly on several aspects, including using types of citations, the variety of the citations based on the type of the clauses in each citation, and the perspectives of EFL Arab postgraduates on using citations. A purposeful sampling was adopted in selecting the literature review of $20 \mathrm{PhD}$ theses and nine EFL Arab candidates of Applied Linguistics and Information Technology. The results show the dominance of the integral citation in the literature review of Applied Linguistics and Information technology. The inter-disciplinary comparison also reported similarity in terms of the high frequency of using citations with clauses complexes. The discourse-based interviews revealed that EFL Arab postgraduates depended on the integral citation to highlight ideas, attract the reader's attention, affirm the credibility of the cited information, and refer to the type of the information. The little available information on using citations and the possible effect of their native language may lead EFL Arab postgraduates to have their own strategies regarding citations use. Consequently, EFL postgraduate students probably need explicit instructions on the use of citations.
\end{abstract}

(C) 2019 EJAL \& the Authors. Published by Eurasian Journal of Applied Linguistics (EJAL). This is an open-access article distributed under the terms and conditions of the Creative Commons Attribution license (CC BY-NC-ND) (http://creativecommons.org/licenses/by-nc-nd/4.0/).

Keywords: Academic writing; citations; EFL Arab postgraduates; literature review; PhD theses

\section{Introduction}

Several studies have been conducted on citations (Harwood, 2009; Hu \& Wang, 2014; Hyland, 1999; Jomaa \& Bidin, 2016, 2017; Mansourizadeh \& Ahmad, 2011; Monreal \& Salom, 2011; Nguyen \& Pramoolsook, 2015, 2016; Petric`\& Harwood,

\footnotetext{
* Corresponding author.

E-mail address: nayefjomaa@karabuk.edu.tr

† siti764@uum.edu.my
} 
2013; Rabab'ah \& Al-Marshadi, 2013; Rowley-Jolivet \& Carter-Thomas, 2014; Samraj, 2013; Shi, 2012; Swales, 1990, 2014; Thompson, 2001; Thompson \& Tribble, 2001; Yang, 2013). These studies addressed the citations types, subcategories of the integral and non-integral citations, functions of citations, purposes of citations, reporting verbs in citations, roles of the cited author in the integral citation, and challenges in the citation process. This increasing interest in studying citations in academic texts demonstrates the significance of citations as the most obvious proof that a text is really academic (Swales, 2014). Asserting the genre as an academic text is not the only function of citations. Rather, it extends to involve the stance of the writer, such as justifying the arguments, indicating gaps in the previous studies, and positioning the writer within the academic community (Hyland, 1999). The necessity to provide students with enough instructions on using citations has been suggested by several studies (Gol, Hezareh, \& Soghondikolaei, 2014; Hu \& Wang, 2014; Jomaa \& Bidin, 2016, 2017; Manan \& Noor, 2015; Maroko, 2013; Nguyen \& Pramoolsook, 2015, 2016; Petric', 2007; Rabab'ah \& Al Marshadi, 2013). However, limited studies have focused on examining the citations, the types of clauses used in each citation, and the reasons that lie behind students' use of each citation type, particularly in the academic writing of EFL Arab students in the public Malaysian universities as an ESL context.

As Swales (2014) argues, the variety in using citations does exist due to unknown reasons. For example, the discipline to which the genre belongs may influence the use of citations (Harwood, 2009; Hu \& Wang, 2014; Hyland, 1999, 2009; Okamura, 2008; Petric` \& Harwood, 2013; Shi, 2012; Thompson, 2002; Thompson \& Tribble, 2001). The writer's native language can also affect the citations performance (Hu \& Wang, 2014; Monreal \& Salom, 2011; Rowley-Jolivet \& Carter-Thomas, 2014). Novice writers and expert ones who belong to the same academic community may also use citations differently (Mansourizadeh \& Ahmad, 2011; Samraj, 2013) as well as using citations in research articles can be different from using citations in writing $\mathrm{PhD}$ theses (Charles, 2006; Samraj, 2013; Yang, 2013). The variation also exists in the genres of the different domains. For further clarifications, $\mathrm{PhD}$ theses in arts disciplines are established on the strength of the arguments, involving more personality and subjectivity. On the other hand, $\mathrm{PhD}$ theses of science disciplines employ less argument; they are foregrounded on factual information (Parry, 1998). These differences support the traditional division that classifies natural sciences and technology on one side as hard disciplines, whereas humanities are on the other side as soft ones (Coffin, et al., 2003). Each discipline in each domain has its own ideology that entails differences in citation practices; therefore, employing general principles in citation practices may not be acceptable because the citation use cannot be 'valid in certain contexts' (Shi, 2012, p.145).

Swales $(1990,2014)$ divided citations into two types: the integral citation and the non-integral one. In the integral type of citations, the cited author is integrated with the structure of the clause to function as a subject, an agent or a part of a noun phrase (Swales, 2014). These roles of the cited author were extended by Jomaa and Bidin (2016) to present a comprehensive taxonomy through applying the interpersonal and 
the ideational (experiential) metafunction of the Systemic Functional Linguistics. On the other hand, in the non-integral type of citation, the name of the cited author is put in parentheses or represented by a number. In another study, Thompson $(2001,2002)$ subcategorized the integral citation into three subcategories: Naming, Verb controlling, and Non-citation, whereas the non-integral citation was categorized into Source or Attribution, Identification, Reference, and Origin. Although such citation types and subcategories equip writers with the basic knowledge, these subcategories present insufficient demonstration, particularly the citations that include more than one clause with more than one subcategory in the same citation.

Few studies have been conducted on the use of citations by EFL Arab students. For instance, Rabab'ah and Al-Marshadi (2013) analysed five MA theses by Saudi students and five MA theses by English native writers adopting the two classifications of Swales (1990) and Thompson and Tribble (2001). The citation density by the Saudi writers was higher than the native writers. Such a result is similar to the Iranian writers of MA of Applied Linguistics in Oskueia and Kuhi's (2014) study. This implies that non-native speakers of English, such as the Saudi writers and the Vietnamese postgraduates in Nguyen and Pramoolsook's (2015) study, lack the linguistic competence; therefore, they had a difficulty in rephrasing the information or adding their own ideas into their writings. The Saudi writers were also similar to the novice writers in Mansourizadeh and Ahmad's (2011) study in using the integral verbs more than noun-phrase citations. Although EFL MA theses belong to the soft domain in which the integral citation is usually dominant, the Saudi writers used non-integral citations more than their native counterparts, whereas the EFL Iranian writers in Gol et al.'s (2014) study used the integral citations more than the non-integral ones. This shows that the performance of the Saudi writers is in contrast with the use of citations in Hyland's (1999) study, in which the integral citation was used more in the research articles of the soft domain, whereas the nonintegral citation was used more in the research articles of the hard domain.

Hyland's study was based on a corpus of 80 research articles chosen from eight disciplines to represent a broad area of academic practice. The 80 articles were chosen randomly from journals that were considered as the most important ones in their fields. His study also included interviews with a well-published researcher from each discipline to explore the citation practices in academic writing. In this regard, Gardner (2012) argues that understanding how the meanings are structured in the context requires the examination of texts and practices. In a recent study by Jomaa and Bidin (2017), it was pointed out that EFL Arab postgraduates face challenges in terms of citations use associated with addressing the credibility of the information in some sources, revealing a stance, limited knowledge about citations use, and second language difficulties. Due to these contrasts in the findings and lack of studies on EFL Arab PhD students' perceptions and use of citations, this study attempts to address several questions that are related to the citations use. 
1. What are the citations types used by EFL Arab postgraduates in the literature review of Applied Linguistics and Information Technology PhD theses?

2. How does the citation type differ based on the type of clauses in the literature review of Applied Linguistics and Information Technology $\mathrm{PhD}$ theses?

3. What are the perspectives of EFL Arab PhD candidates of Applied Linguistics and Information Technology towards using citations in the literature review of their $\mathrm{PhD}$ proposals?

\section{Method}

\subsection{Research design}

The present study adopted Swales' (1990) classification of the citation types, focusing mainly on analysing the citations in the literature review of $20 \mathrm{PhD}$ theses by EFL Arab postgraduates at a public Malaysian university. The Systemic Functional Linguistics (Halliday \& Martin, 1993) was also adopted in identifying the citations with clause simplexes and citations with clause complexes. Hence, the citations that were analysed represented the micro (sentence) level of analysis because each citation that was analysed is a complete sentence. Each sentence with a single citation or multiple citations was considered as one citation.

The study employed the qualitative analysis that was enhanced by quantifying the findings in order to present the frequency of occurrence and the percentage. Maxwell (1992) stresses that such a technique supports the internal generalizability of the writer's claims and assists in identifying inapparent features as well as attributing particular patterns to the participants who are involved in the study. The technique of quantifying the findings also assists the researcher's interpretation in opposing the claim that qualitative researchers select only what supports their arguments (Maxwell, 2010).

\subsection{Participants and sampling}

Analysing the citations in the literature review of $20 \mathrm{PhD}$ theses was followed by conducting Discourse-Based Interviews (DBIs) with nine EFL Arab candidates of Applied Linguistics and Information Technology in order to enrich the study with their perspectives on citation use when writing the literature review chapters of their $\mathrm{PhD}$ proposals.

A purposeful sampling was adopted in choosing the literature review of $20 \mathrm{PhD}$ theses in Applied Linguistics and Information Technology by EFL Arab postgraduates. These $\mathrm{PhD}$ theses were accessed through the library of one of the public Malaysian universities. The list of names of the $\mathrm{PhD}$ theses' writers was provided by the graduate studies unit at the university. Using these PhD theses for academic purposes was approved by the Dean of the Graduate Schools at the university. The details of these $\mathrm{PhD}$ theses are presented in Tables (1) and (2). 
Table 1. Descriptions of PhD theses of applied linguistics

\begin{tabular}{lllllll}
\hline No & $\begin{array}{l}\text { Coding of } \\
\text { Thesis }\end{array}$ & Nationality & $\begin{array}{l}\text { Publication } \\
\text { Date }\end{array}$ & $\begin{array}{l}\text { Number of } \\
\text { Pages }\end{array}$ & $\begin{array}{l}\text { Number of } \\
\text { Words }\end{array}$ & \begin{tabular}{l} 
Citation Style \\
\hline 1
\end{tabular} \\
\hline LR.1 & Iraqi & 2013 & 35 & 9,031 & (Author, date) style \\
2 & LR.2 & Jordanian & 2014 & 75 & 20,744 & (Author, date) style \\
3 & LR.3 & Jordanian & 2014 & 87 & 21,661 & (Author, date) style \\
4 & LR.4 & Yemeni & 2014 & 62 & 12,139 & (Author, date) style \\
5 & LR.5 & Yemeni & 2014 & 35 & 8,990 & (Author, date) style \\
6 & LR.6 & Iraqi & 2014 & 69 & 18,149 & (Author, date) style \\
7 & LR.10 & Jordanian & 2013 & 88 & 21,541 & (Author, date) style \\
8 & LR.11 & Libyan & 2014 & 89 & 22,080 & (Author, date) style \\
9 & LR.12 & Iraqi & 2013 & 117 & 31,872 & (Author, date) style \\
10 & LR.19 & Yemeni & 2015 & 79 & 19,000 & (Author, date) style \\
Total & \multicolumn{2}{c}{ 10 } & & 736 & 185,207 & \\
& \multicolumn{2}{c}{ PhD theses } & pages & words & \\
\hline
\end{tabular}

Ten $\mathrm{PhD}$ theses belong to the Information Technology discipline (IT) as a hard domain of knowledge, in which the numbering style was used in the citation in three $\mathrm{PhD}$ theses, whereas (author, date) style was used in the other seven $\mathrm{PhD}$ theses. On the other hand, ten $\mathrm{PhD}$ theses belong to the Applied Linguistics discipline (AL) in the soft domain of knowledge, in which the (author, date) style was used in the ten $\mathrm{PhD}$ theses.

Table 2. Descriptions of PhD theses of information technology

\begin{tabular}{|c|c|c|c|c|c|c|}
\hline No & $\begin{array}{l}\text { Coding of } \\
\text { Thesis }\end{array}$ & Nationality & $\begin{array}{l}\text { Publication } \\
\text { Date }\end{array}$ & $\begin{array}{l}\text { Number } \\
\text { of Pages }\end{array}$ & $\begin{array}{l}\text { Number of } \\
\text { Words }\end{array}$ & Citation Style \\
\hline 1 & LR.7 & Syrian & 2014 & 69 & 13,815 & Numbering style \\
\hline 2 & LR. 8 & Iraqi & 2013 & 73 & 18,526 & (Author, date) style \\
\hline 3 & LR.9 & Iraqi & 2014 & 72 & 16,005 & (Author, date) style \\
\hline 4 & LR.13 & Jordanian & 2011 & 65 & 14,743 & (Author, date) style \\
\hline 5 & LR.14 & Jordanian & 2012 & 60 & 13,162 & (Author, date) style \\
\hline 6 & LR.15 & Palestinian & 2012 & 37 & 8,547 & Numbering style \\
\hline 7 & LR.16 & Yemeni & 2014 & 49 & 10,093 & Numbering style \\
\hline 8 & LR.17 & Jordanian & 2011 & 54 & 12,702 & (Author, date) style \\
\hline 9 & LR.18 & Iraqi & 2014 & 70 & 13,380 & (Author, date) style \\
\hline 10 & LR.20 & Jordanian & 2012 & 107 & 27,410 & (Author, date) style \\
\hline Total & \multicolumn{2}{|c|}{10} & & 656 & 148,383 & \\
\hline & \multicolumn{2}{|c|}{ PhD theses } & & pages & words & \\
\hline
\end{tabular}

The extracted examples from the literature review of each $\mathrm{PhD}$ thesis were employed in order to support the findings and explain the citation use. Table 3 demonstrates the coding used with each extract. 
Table 3. Coding the extracted citations

\begin{tabular}{lll}
\hline Literature Review & Discipline & Nationality \\
\hline LR.1 & AL & Iraqi: IR \\
LR.7 & IT & Syrian: SY \\
\hline
\end{tabular}

The present study also adopted discourse-based interviews with nine EFL Arab doctoral students at one of the public Malaysian universities. The nine EFL Arab participants were selected purposefully because Creswell (2012) suggested that in qualitative studies, the purposeful sampling is used to identify the participants who can assist in getting a clear understanding of the phenomenon. Four criteria were employed to select the participants; first, they were EFL PhD students. Second, they belong to Arab countries. Third, they have passed their PhD proposals successfully. Fourth, they were from Information Technology and Applied Linguistics disciplines. It was difficult to interview the authors of the $20 \mathrm{PhD}$ theses which were analysed because the majority had returned to their home countries. Consequently, the interviews were conducted with EFL Arab PhD candidates who are still involved in their $\mathrm{PhD}$ study to reflect on their own citation practices. These interviews, according to Mackey and Gass (2005), can increase the validity and reliability of the students' reports because the time is short between the event of writing the literature review chapter and the reflection on their citation practices.

As Creswell (2008) argues, the aim of qualitative studies is not to generalize the findings. Rather, they explore a specific phenomenon deeply and comprehensively; therefore, obtaining diverse perspectives from EFL Arab participants is significant and this variety in the participants' perception is a distinguished aspect of qualitative studies in order to convey the complexity of the phenomenon. Table 4 presents detailed information about the nine participants, their country, department, degree, and the length of the interview for each.

Table 4. Background details of nine participants

\begin{tabular}{|c|c|c|c|c|}
\hline Participant & Country & Department & Degree & $\begin{array}{l}\text { Length of } \\
\text { the interviews }\end{array}$ \\
\hline Ali & Yemen & Information Technology & A PhD student & 1 hour, 4 minutes \\
\hline Mohammad & Jordan & Applied Linguistics & A PhD student & 22 minutes \\
\hline Sami & Libya & Information Technology & A PhD student & 48 minutes \\
\hline Ahmad & Iraq & Information Technology & A PhD student & 1 hour, 17 minutes \\
\hline Emad & Syria & Information Technology & A PhD student & 1 hour, 30 minutes \\
\hline Majed & Iraq & Information Technology & A PhD student & 56 minutes \\
\hline Noor & Iraq & Applied Linguistics & A PhD student & $\cdots$ \\
\hline Khalid & Jordan & Information Technology & A PhD student & 58 minutes \\
\hline Leen & Iraq & Applied Linguistics & A PhD student & -....- \\
\hline
\end{tabular}

Face-to-face individual interviews with seven EFL PhD Arab students were conducted because in qualitative studies, it is typical to study few cases or individuals 
"ranging from 1 or 2 to 30 or 40" (Creswell, 2008). Dörnyei (2007) also suggests that interviews with six to ten participants might be suitable. However, two female participants (Noor and Leen) were contacted through their husbands due to religious, social and cultural considerations. Therefore, the interview questions were sent by emails to these two participants and the answers to the questions were also received by email. Another point to mention regarding the participants in Applied Linguistics discipline is that their answers to the interview questions were in English, whereas the six participants in Information Technology discipline answered in Arabic based on their own choice.

The study depended mainly on analysing the citations in the literature review chapters of $20 \mathrm{PhD}$ theses in Applied Linguistics and Information Technology. Based on these analyses, open-ended and semi-structured interview questions were formulated. These interview questions were modified and improved based on a pilot study with two EFL Arab doctoral students. The interviews were based on the writing of the participants. That is, Discourse-Based Interviews (DBIs) were employed since, as Patton (1990) argues, interviews enable the researcher to get the inner perspectives of the participant. DBI that was developed by Odell, Goswami, and Herrington (1983) is advocated by Lancaster (2016) since these DBIs can be used to effectively explore the writers' choice in their writing performance. In this aspect, Hyland advocates text-based interviews as 'a means of capturing disciplinary language use, both in its regularities and in its variations, on a sufficiently large scale" (Swales, 2013, p.1). Discourse-Based Interviews and Text-Based Interviews, as Hyland replied to a question sent to him via academia, "are the same in most cases discussing a text or a transcript with a writer or a reader."

Based on the recommendation of Dörnyei (2007), the interviews were conducted in the participant's L1 like Nguyen and Pramoolsook's (2016) study. Hence, the Arabic language was used by the participants, particularly in Information Technology department. An appointment was determined and the interviews were tape-recorded. After transcribing the interviews, they were translated into English. A hand analysis, mind mapping, and visual mapping were adopted in the data analysis. Besides the member checking, as suggested by Creswell (2008), the credibility of the findings was supported by quoting some of the participants' perspectives.

\section{Results}

The findings address the following aspects: types of citations, types of clauses used in each type of citation, and the perspectives of EFL Arab candidates on the citations use when writing the literature review chapters of their $\mathrm{PhD}$ proposals.

\subsection{Types of citations}

EFL Arab postgraduates employed two main types of citations which are the integral citation and the non-integral one as well as a mixed type of citation and quotations. 


\subsection{Integral citation}

In the integral citation, the name of the cited author is integrated with the clause of citation to represent one of its constituents, as demonstrated in examples (1) and (2).

(1) 'According to Biber, et al. (1998), language is distinguished by structure and use."(LR.2/AL/JO)

(2) "Schneier (1996) posits that system security can be strengthened by several modes of operations, namely, ECB, CBC, Cipher Feedback (CFB), Output Feedback (OFB), and Counter (CTR) modes." (LR.9/IT/IR)

The integral citation was used with either a single citation or multiple citations. In single citations, only one citation referring to one source is used as in example (3).

(3) 'O'Sullivan (2003) believes that societies have always needed effective and efficient means of transmitting information and mass communication is the outgrowth of this need." (LR.12/AL/IR)

On the other hand, the integral citation with multiple citations involved more than one citation that refers to different sources with different authors, as in example (4).

(4) 'King (1998) described alignment as the fit of IT strategies and plans with business strategies and goals, whereas Kanellis et al. (1999) stated that alignment is the fit between an organization and its strategy, structure, processes, technology and environment." (LR.17/IT/JO)

In the literature review of $\mathrm{PhD}$ theses that used Numbering Style, the integral citation was distinguished by using numbers with the name of the cited author or instead of it. In some cases, only the prepositions, such as 'in' or 'by' were used to integrate the numbering system that represents the cited author with the structure of the clause. Example (5) demonstrates such a use.

(5) 'For example, in [22] the authors consider NoA only in the current time interval". (LR.15/IT/PA)

Table 5 below illustrates the number and the percentage of the integral citations used in the literature review of Applied Linguistics and Information Technology.

Table 5. Integral citations in the literature review of AL and IT theses

\begin{tabular}{lll}
\hline Discipline & Number & Percentage \\
\hline Applied Linguistics & 2350 & $66.40 \%$ \\
Information Technology & 1184 & $54.58 \%$ \\
\hline
\end{tabular}

Despite their different domains of knowledge, the integral type of citation dominated the literature review of Applied Linguistics and Information Technology. The inter-disciplinary comparison showed the possible influence of the ethnolinguistic factor of EFL Arab postgraduates on using citations in the two domains. This could reveal that the background of the writer should be considered when analysing language use, particularly citations in academic genres. On the other hand, the intradisciplinary investigation reported the influence of the field on the high use of the integral citation compared to other types of citations in the literature review of 
Applied Linguistics. This latter finding is in line with the citation practices in the soft domain of knowledge in which the integral citation is preferred.

On the other hand, using the integral citation more than other types of citations in the literature review of Information Technology is in contrast with the citation performance in the hard domains of knowledge. A possible reason can be attributed to the insufficient instructions on using citations. In other words, EFL Arab postgraduates in the hard domain of knowledge may be unaware of the implied evaluation in using either type of citations.

\subsubsection{Non-Integral Citation}

In the non-integral citation, the name of the cited author is not integrated with the structure of the clause. Rather, it is used in parentheses. Example (6) demonstrates this type of citation.

(6) 'People use language to express feelings and elicit meaning (Lyon, 1968, p. 424)". (LR.1/AL/IR)

Like the integral type of citation, the non-integral citation can be a single citation as in example (7) or multiple citations as in example (8).

(7) "After the pattern classification systems are built, it is an extremely important concern to assess the systems' executions (Tsai, 2010).” (LR.8/IT/IR)

(8) "CBIR has two key performance factors, which are retrieval accuracy and retrieval time, the time needed for retrieving the results (Aulia, 2005; Datta, et al., 2008; Howarth, 2007; Pavlidis, 2008)." (LR.18/IT/IR)

Table 6 below shows the number and the percentage of using the non-integral citation in the literature review of Applied Linguistics and Information Technology theses.

Table 6. Non-integral citations in the literature review of AL and IT theses

\begin{tabular}{lll}
\hline Discipline & Number & Percentage \\
\hline Applied Linguistics & 1079 & $30.48 \%$ \\
Information Technology & 917 & $42.27 \%$ \\
\hline
\end{tabular}

The use of the non-integral citation followed the integral citations in terms of number and percentage in the literature review of Applied Linguistics and Information Technology. Using the non-integral citation with a lower percentage is in line with the norms of citations followed in soft disciplines. This shows the disciplinary influences on using citation in Applied Linguistics as a field of the soft domain. On the other hand, the non-integral citation occupied a lower number of frequencies which contrasts with the general conventions of using citations in the hard domain. In other words, Information Technology belongs to the hard domain in which the non-integral is preferred; therefore, it should be used more than the integral citation because of the less prominent role for the cited author. This citation performance probably implies the possible influences of the ethnolinguistic factors 
and receiving insufficient guidelines and instructions on how to use citations appropriately in each discipline.

\subsubsection{Mixed citation (integral and non-integral citation)}

Citations by EFL Arab postgraduates also included a mixed type of citations in which the integral and the non-integral citation were used in the same citation, as in example (9) below.

(9) 'In spite of the fact that her classification of the five categories seems to be overlapping and not quite distinct, Salager-Meyer's study is quite revealing in showing the different distribution of hedging categories (Crompton, 1997)." (LR.4/AL/YE)

In example (9), the integral citation represented by the name of the cited author 'Salager-Meyer' and the non-integral citation represented by the name of the cited author 'Crompton' are used in one citation.

Table 7 demonstrates the number and the percentage of using this mixed type of citation in the literature review of Applied Linguistics and Information Technology.

Table 7. Mixed type of citation in the literature review of AL and IT theses

\begin{tabular}{lll}
\hline Discipline & Frequency & Percentage \\
\hline Applied Linguistics & 96 & $2.71 \%$ \\
Information Technology & 60 & $2.76 \%$ \\
\hline
\end{tabular}

In both Applied Linguistics and Information Technology, the mixed type of citation occupied the third rank in terms of frequencies of occurrences and percentage, following the integral and non-integral citations. Using a mixed type of citation may reflect the attempt of EFL Arab postgraduates to highlight a specific idea through presenting reliable and credible information by means of using more than one source.

\subsubsection{Quotations}

Quotations were used in two different ways; one of these ways was to integrate the name of the cited author to be a part of a prepositional constituent. Thus, this type of quotation was classified under the integral citation, as in example (10).

(10) Surprisingly, in Huang's (2010) words, "motivation was gauged by one item: I enjoy speaking English" (p. 93). (LR.19/AL/YE)

Fifteen quotations of this type were used in the literature review of Applied Linguistics, whereas only two quotations were used in the literature review of Information Technology. The other way was through presenting quotations with the non-integral citation; the name of the cited author is put in parentheses, and it does not have any role in the clause of the citation. Example (11) demonstrates such a type of quotations.

(11)"........ In addition to the objective temporal relationship between the time of a situation...and speech time, the speaker's point of view and purpose in communicating play a crucial role in the choice between the past and present tenses? A situation whose time frame extends from the past to the present may 
be described in the past...if the purpose is to present information or ask a question from a past point of view." (Shankman, 1993, p. 269). (LR.6/AL/IR)

Fourteen quotations were used in the literature review of Applied Linguistics, whereas eight quotations were used in the literature review of Information Technology. Though quotations were used with a small number and percentage compared with the integral and non-integral citations, their use was higher in the literature review of Applied Linguistics. This may reveal the disciplinary influence of Applied Linguistics as a field of the soft domains on the use of quotations. That is, EFL Arab postgraduates in Applied Linguistics depended more on the cited author's words to support their arguments. In addition, using quotations rather than paraphrasing might be attributed to the inability of EFL Arab postgraduates to paraphrase the information in a way that keeps the original meaning and shows the stance of the writer. On the other hand, in Information Technology, the focus was not on quoting words. Rather, it was on procedures, facts, and findings. Therefore, quotations were less used.

\subsection{Citations with clause complexes and clause simplexes}

The type of clauses used in citations can be another characteristic for the differentiation between the domains of knowledge. This was evident through identifying two types: citations with clause complexes and citations with clause simplexes.

\subsubsection{Citations with clause complexes}

Citations with clause complexes involved using more than one clause in a citation; these clauses are joined either hypotactically or paratactically, that are illustrated respectively in the two examples (12) and (13).

(12) 'On the other hand, Hettich (1994) states that writing apprehension has not been clearly defined". (LR.3/AL/JO)

(13) "Tan and Teo (2000) applied the DTPB to investigate the acceptance of Internet banking in Singapore." (LR.20/IT/JO)

Table 8 below presents the frequency and the percentage of using citations with clause complexes in the literature review of Applied Linguistics and Information Technology.

Table 8. Citations with clause complexes in the literature review of AL and IT theses

\begin{tabular}{lll}
\hline Discipline & Frequency & Percentage \\
\hline Applied Linguistics & 2666 & $75.33 \%$ \\
Information Technology & 1593 & $73.44 \%$ \\
\hline
\end{tabular}

Citations with clause complexes dominated the literature review of Applied Linguistics and Information Technology theses. This may reveal the influence of EFL Arab postgraduates' native language on using citations; their native language (Arabic) can have an effect on using citations represented by long statements that involve 
more than one clause in a citation. The overuse of conjunctions, including the structural conjunctions 'that' and 'which' which exist in Arabic language might be transferred by EFL Arab students to be structured similarly in English. Another reason for using citations with clause complexes was the effect of the type of the citation. In other words, the dominance of the integral citation resulted in the high density of citations with clause complexes, as demonstrated in Table 9.

Table 9. Citations with clause complexes in each type of citation

\begin{tabular}{|c|c|c|c|c|c|c|c|}
\hline \multirow[t]{2}{*}{ Discipline } & \multicolumn{2}{|c|}{ Integral } & \multicolumn{2}{|c|}{ Non-integral } & \multicolumn{2}{|c|}{ Mixed } & \multirow[t]{2}{*}{ Total } \\
\hline & $\mathrm{F}$ & $\%$ & $\mathrm{~F}$ & $\%$ & $\mathrm{~F}$ & $\%$ & \\
\hline Applied Linguistics & 1815 & 68.07 & 774 & 29.03 & 77 & 2.88 & 2666 \\
\hline Information Technology & 932 & 58.50 & 607 & 38.10 & 54 & 3.38 & 1593 \\
\hline
\end{tabular}

Based on the findings demonstrated in Table 9, the integral type includes the highest number of citations with clauses complexes, followed by the non-integral citations, whereas the mixed type of citations has the lowest number of citations with clause complexes. Although Applied Linguistics and Information Technology are of two different domains, the findings presented in Table 9 show similarities in terms of employing the citations in using clause complexes.

\subsubsection{Citations with clause simplexes}

EFL Arab postgraduates also used the integral citation, the non-integral citation, and the mixed type of citation with clause simplexes, as in example (14).

(14) "In the last two decades, studies by Casanave and Hubbard (1992) looked into supervisor's perceptions of the postgraduate student's (L2) difficulties during thesis writing." (LR.3/AL/JO)

The findings related to citations types used with clauses simplexes are illustrated in Table 10.

Table 10. Citations with Clause Simplexes in the Literature Review of AL and IT Theses

\begin{tabular}{llllllll}
\hline Discipline & Integral & \multicolumn{2}{l}{ Non-integral } & \multicolumn{2}{l}{ Mixed } & \multicolumn{2}{c}{ Total } \\
\hline & $\mathrm{F}$ & $\%$ & $\mathrm{~F}$ & $\%$ & $\mathrm{~F}$ & $\%$ & \\
Applied Linguistics & 520 & 61.61 & 305 & 36.13 & 19 & 2.25 & 844 \\
Information Technology & 250 & 44.16 & 310 & 54.77 & 6 & 1.06 & 566 \\
\hline
\end{tabular}

The citations with clauses simplexes occupied a lower number and percentage in the literature review of Applied Linguistics and Information Technology. The interdisciplinary comparison shows that Applied Linguistics, as a soft domain, has more citations with clause simplexes; this reveals the disciplinary influence represented by field on the use of citations. The type of citation also affected the use of the clause simplexes. For example, in the literature review of Applied Linguistics, the integral citation included the highest number of citations with clause simplexes, followed by the non-integral citation, and the mixed type of citation. On the other hand, in the literature review of Information Technology, the non-integral citation had the highest 
number of citations with clause simplexes, followed by the integral citation and the mixed type of citation. These differences reflect the disciplinary influence represented by field as a register variable that probably affects the use of citations and type of clauses.

\subsection{Perspectives of EFL students on using types of citations}

Using either type of citations (the integral or the non-integral citation) was led by EFL Arab postgraduates' own perspectives. Hence, four main reasons underlined students' use of citations. These included highlighting ideas, attracting the reader's attention, asserting the credibility of the cited information, and a signal of the source of the cited information.

\subsubsection{Highlighting ideas}

For some participants in Information Technology, although they belong to the hard domain of knowledge in which the focus is on facts, the integral citation for them was used to highlight the idea because the three elements involved in the integral citations, such as the name of the author, the year of publication, and the number of the reference, emphasize the importance of the idea of the reported information.

The integral citation emphasizes the information and attracts the reader to something that is very important because you mention the name of the author, the year, as well as the citation itself. (Ali)

Frankly, in my thesis or in my study, I used example 3 (non-integral citation) and example 4 (integral citation), but when I want to emphasize and highlight an idea, and when I want to highlight and do not want to say that this is my idea, I use the author's name together with the reference.(Khalid)

When mentioning the name of the author with the number, it is a sort of more emphasis, and I feel that it is stronger information. (Emad)

For the participants in Information Technology, the integral citation emphasizes the significance of the idea, and this may justify the high use of the integral citation in the literature review of Information Technology. However, for other participants, the non-integral citation gives more emphasis to the information, particularly when used with multiple citations.

If I have an idea and more than one author supports it, sometimes, I write one complete paragraph and at end of the paragraph I use multiple citations (referring to his proposal) like page 39 in chapter two. (Ahmad)

They (integral and non-integral citations) are different in my point of view. I prefer the non-integral citation because the researcher feels his arguments are given more strength and power. (Mohammad) 
The diversity in the perspectives of EFL Arab postgraduates on using citations is probably because of the insufficient knowledge on using hedges or boosters that can be used to enhance the argument and demonstrate the position of the writer. Hence, they used citations to reveal their authorial stance.

\subsubsection{Attracting the reader's attention}

The other reason for using the integral citation was to attract the reader's attention to something that is very important; therefore, the integral citation is used when the reader may lose interest in reading.

All citations are important, but in integral citations, it is as if you are addressing someone to call him for an important thing. The two types of citations are important, but their representation implies that if the reader lost interest in reading, it implies to call him back again because the style of writing the integral citation involves the name of the author, the year, as well as the citation; these three things imply to give me your attention because here is something different. (Ali)

I try to use a combination of the two styles in order for the reader not feeling bored. I use both types in each page of my writing. Sometimes in order not to make the sentence repetitive, I use this combination. If you follow one style, there will be a kind of possible monotony for the reader. I think, based on my personal view, we have to make a kind of combination in order to make writing more interesting. (Ahmad)

The variety in using either type of citation implies that EFL Arab postgraduates use citations randomly with the purpose of making reading more interesting to the reader. This reveals their attempt to make their writing style and the flow of ideas go smoothly. However, the random choice of citations entails unawareness of the implicit evaluation of the citation use.

\subsubsection{Type of the information source}

Using either type of citations according to the perspectives of some participants is determined by the type of the information cited from the sources. For example, based on the participants' views, in citing general information, the non-integral citation was used, whereas the integral citation was used to refer to a particular study.

I use mostly the non-integral citation when citing from book references or theses because it is a kind of general information, such as a definition of the problem or an introduction to the area, so it is only general information; therefore, I use the non-integral citation (referring to his proposal on page 29). When the author refers to specific points, I use the integral citation, but if I found that it is only general information that does not deserve to be put as points to be highlighted, I use the non-integral citation. (Sami)

Hence, the two types of citations were used by EFL Arab postgraduates based on the quality of the information. For example, information that is cited from books and $\mathrm{PhD}$ theses was used employing the non-integral citation. On the other hand, the information that refers to specific studies was used by means of the integral citation. 
Consequently, the dominance of the integral citation in the literature review possibly demonstrates that EFL Arab postgraduates try to cite information that is so specific and closely related to their research topics.

\subsubsection{Credibility of the cited information}

Based on the participants' views, using the integral citation also stresses the credibility of the cited information, particularly when the name of the cited author refers to an expert in the field of the research. This, according to the claims of the participants, will increase the credibility of the cited information and make the examiners/readers sure that the cited information is definitely true.

Frankly, for me, I prefer the integral citation because it clarifies to the reader where did you cite the information from, and if the person is expert in the area. If the cited person is expert in the area, I think this will support your study mainly because the experts in the area have a lot of published articles, and there is no doubt in their works. So, when you find the name of the author, it will motivate you that, is this author honest in citing the sentence? and this depends on the name of the author itself and depends where the paper was published. (Majed)

When the examiner reads, he will be an expert in my field. When he reads that the cited author has said this and this, then this point will not be questionable. (Khalid)

The integral citation according to the participants' views was also used in order to deliver a message to the reader and the examiner. In other words, the cited authors who are experts in the field of research would be employed in the integral citation because they have long experience in researching and publication. Therefore, their works would be true and unquestionable. In conclusion, citations were used by EFL Arab postgraduates to highlight ideas, attract the reader's attention and assert the credibility of the cited information. The two types of citations were also used to differentiate the type of the cited information and the source from which it was cited.

\section{Discussion}

The present study explored the citation use by EFL Arab postgraduates in writing the literature review chapters of $\mathrm{PhD}$ theses of Applied Linguistics and Information Technology based on Swales' (1990) classification. EFL Arab postgraduates employed the integral citation, the non-integral citation, a mixed type of integral and nonintegral, and quotations. The findings showed the dominance of the integral citation with (66.40\%) in Applied Linguistics and (54.58\%) in Information Technology, followed by the non-integral citation with (30.48\%) in Applied Linguistics and (42.27\%) in Information Technology. On the other hand, the mixed type of citations and quotations occupied a lower number of frequencies.

It was also revealed that the citations with clause complexes were used with a higher frequency in the literature review of Applied Linguistics ( $n=2666)$ and Information Technology ( $\mathrm{n}=1593)$, whereas citations with clause simplexes had a lower number of frequencies $(n=844)$ in Applied Linguistics and $(n=566)$ in 
Information Technology. The integral citation had the highest number of clause complexes in the literature review of Applied Linguistics ( $\mathrm{n}=1815)$ and Information Technology $(\mathrm{n}=932)$, followed by the non-integral citation with $(\mathrm{n}=774)$ in Applied Linguistics and $(n=607)$ in Information Technology. However, the mixed type of citation had the lowest number of clause complexes with $(n=77)$ in Applied Linguistics and $(n=54)$ in Information Technology. As for the citations with clause simplexes, they were used with a lower number of frequencies $(n=844)$ in Applied Linguistics and $(\mathrm{n}=566)$ in Information Technology, compared with the citations with clause complexes. The study also involved discourse-based interviews with EFL Arab candidates of Applied Linguistics and Information Technology. The findings reported that the integral citation was used to highlight the important ideas, attract the reader's attention, and assert the credibility of the cited information. The type of the information source was also a determinant factor in selecting either type of citations.

Using the integral citation with a higher percentage in the literature review of Applied Linguistics is in line with the findings of Hyland (1999), in which research articles of the soft domain included a high number of the integral citation. However, the dominance of the integral citation in the literature review of Information Technology is in contrast with the citation practices of the research articles in the hard domain. Such a performance may reveal EFL Arab postgraduates' unawareness of citation evaluation, thus employing their own strategies to persuade their readers of the strength of their argumentation through using the integral citation. Hence, as Borg (2000) concludes, non-native speakers of English are less skilled in establishing textual voice, and this poses further challenges on them. By comparing the citation use of Saudi students in Rabab'ah and Al-Marshadi's (2013) study with the citations use in the literature review of EFL Arab postgraduates in the present study, it seems that they are contrasting though the two genres in the two studies belong to the soft domain.

Despite limiting the study to only EFL Arab students' use of citations in the literature review of two disciplines, the findings show EFL postgraduates' lack of sufficient guidelines and instructions on using citations. For example, students' employment of using the integral citation as a technique to highlight ideas and stress the credibility of the information may entail that EFL Arab students are unaware of the implied evaluation of citation. Instead of using evaluative expressions to show their stance towards the reported information, the integral citation was used to reveal their attitude in order to convince the reader and the examiner of their arguments. This sheds light on the attempts by EFL Arab postgraduates to position themselves within the research area. In addition, lack of knowledge of the evaluative devices such as hedges and boosters did not enable EFL Arab postgraduates to be appropriately critical in their writings. This shows that non-native speakers of English find difficulty in learning the use of citations implicitly through reading sources, such as articles and theses (Mansourizadeh \& Ahmad, 2011; Nguyen \& Pramoolsook, 2016). Their native language may also have an effect on their use of citations. This was highlighted in using citations with long statements which might be attributed to the 
overuse of structural conjunctions that have parallels in Arabic language. The effect of the writers' native language on using citations in English was revealed by RowleyJolivet and Carter-Thomas (2014) and Jomaa and Bidin (2017).

\section{Conclusions}

The findings of the present study imply that EFL Arab postgraduates should be provided with sufficient guidelines on citation use and how to utilise hedges and boosters in order to state their positions properly within their academic community. In addition, citations should be taught and learned explicitly (Hu \& Wang, 2014; Nguyen \& Pramoolsook, 2015). In this regard, applying the Systemic Functional Linguistics in analysing citations, as $\mathrm{Hu}$ and Wang (2014) and Jomaa and Bidin (2016) suggested, could result in a comprehensive picture of citation use. Involving information of citations, using hedges, boosters and reporting verbs in textbooks for academic purposes together with authentic materials from students and experts' writings would be beneficial for novice writers. Hence, combining the understanding of students' academic practices in context and the academic text in context would be basically essential for the application of such findings in EAP contexts (Gardner, 2012). Thus, it is possible that having an experimental study will make evidence of the effectiveness of such knowledge in enhancing students' academic writing.

\section{Acknowledgements}

We would like to thank Universiti Utara Malaysia (UUM) for making this study possible. We also would like to thank the $20 \mathrm{PhD}$ students whose theses were analysed as well as the nine participants who enriched the study with their views.

\section{References}

Borg, E. (2000). Citation practices in academic writing. In Thompson, P. (Ed.), Patterns and Perspectives. Insights into EAP Writing Practice (pp. 27-45). Reading: The University of Reading.

Charles, M. (2006). Phraseological patterns in reporting clauses used in citation: A corpusbased study of theses in two disciplines. English for Specific Purposes, 25, 310-331. Doi.org/10.1016/j.esp.2005.05.003

Coffin, C., Curry, M. J., Goodman, S., Hewings, A., Lillis, Th.M., \& Swann, J. (2003). Teaching Academic Writing. USA and Canada: Routledge.

Creswell, J.W. (2008). Educational Research: Planning, Conducting and Evaluating Quantitative and Qualitative Research. (3rdth Edition). USA, Boston: Pearson Education, Inc.

Creswell, J.W. (2012). Educational Research: Planning, Conducting and Evaluating Quantitative and Qualitative Research. (4th Edition). USA, Boston: Pearson Education, Inc.

Dörnyei, Z. (2007). Research Methods in Applied Linguistics: Quantitative, Qualitative and Mixed Methodologies. Oxford, England: Oxford University Press.

Gardner, S. (2012). Genres and registers of student report writing: An SFL perspective on texts and practices. Journal of English for Academic Purposes, 11(1), 52-63. doi:10.1016/j.jeap.2011.11.002. 
Gol, A. K., Hezareh, B. G., \& Soghondikolaei, E. M. (2014). A contrastive study of rhetorical functions of citation in Iranian and international ELT scopus journals. Linguistics and Literature Studies, 2(6), 155-165. doi: 10.13189/ lls.2014.020601

Halliday, M. A. K., \& Martin, J. R. (1993). Writing science: Literacy and discursive power. London: The Falmer Press.

Harwood, N. (2009). An interview-based study of the functions of citations in academic writing across two disciplines. Journal of Pragmatics, 41(3), 497-518. doi:10.1016/j.pragma.2008.06.001.

Hu, G., \& Wang, G. (2014). Disciplinary and ethnolinguistic influences on citation in research articles. Journal of English for Academic Purposes, 14, 14-28. doi.org/10.1016/j.jeap.2013.11.001

Hyland, K. (1999). Academic attribution: citation and the construction of disciplinary knowledge. Journal of Applied Linguistics, 20(3), 341-367. doi.org/10.1093/applin/20.3.341

Hyland, K. (2009). Writing in the disciplines: Research evidence for specificity. Taiwan International ESP Journal, 22. https://www.researchgate.net/publication/267817913_Writing_in_the_disciplines_Research_ evidence_for_specificity

Jomaa, N. J., \& Bidin, S. J. (2016). Roles of the cited author in citations of the literature review by EFL postgraduates. International Journal of Applied Linguistics and English Literature, 5(7), 213-225. doi.org/10.7575/aiac.ijalel.v.5n.7p.213

Jomaa, N. J., \& Bidin, S.J. (2017). Perspective of EFL doctoral students on challenges of citations in academic writing. Malaysian Journal of Learning and Instruction (MJLI), 14(2), 177-209. Retrieved from http://mjli.uum.edu.my/images/vol14no2dec17/177-209.pdf

Lancaster, Z. (2016). Using corpus results to guide the discourse-based interview: A study of one student's awareness of stance in academic writing in philosophy. Journal of Writing Research, 8(1), 119-148. doi:10.17239/jowr-2016.08.01.04

Mackey, A. \& Gass, S.M. (2005). Second Language Research: Methodology and Design. London: LEA.

Manan, N.A. and Noor, N.M. (2015). The use of integral citations in master's degree theses. International Journal of Education and Research, 5(7), pp. 233-246. http://www.ijern.com/journal/2015/July-2015/21.pdf

Mansourizadeh, K., \& Ahmad, U. K. (2011). Citation practices among non-native expert and novice scientific writers. Journal of English for Academic Purposes, 10(3), 152-161. doi.org/10.1016/j.jeap.2011.03.004

Maroko, G. M. (2013). Learning about author positioning in written academic discourse. Argentinian Journal of Applied Linguistics, 1(2), 47-60. https://irlibrary.ku.ac.ke/bitstream/handle/123456789/8824/Learning\%20\%20about\%20author\%20po sitioning....pdf?sequence $=3$

Maxwell, J. (1992). Understanding and validity in qualitative research. Harvard Educational Review, 62(3), 279-300. https://stars.library.ucf.edu/cirs/2331/

Maxwell, J.A. (2010). Using numbers in qualitative research. Qualitative Inquiry, 16(6), 474482. doi.org/10.1177/1077800410364740

Monreal, C. S., \& Salom, L. G. (2011). A cross-language study on citation practice in PhD theses. International Journal of English Studies, 11(2), 53-75. file://C:/Users/shahad/Downloads/149641-Article\%20Text-559371-1-10-20120322\%20(1).pdf

Nguyen, T. T. L., \& Pramoolsook, I. (2015). Citation in Vietnamese TESOL: Analysis of master's thesis introduction chapters. The Asian ESP Journal, 2(1), 95-118. http://asian- 
esp-journal.com/wp-content/uploads/2015/10/AESP-Volume2-Issue1-June-2015new.pdf\#page $=95$

Nguyen, T. T. L., and Pramoolsook, I. (2016). Citations in literature review chapters of TESOL master's theses by Vietnamese postgraduates. GEMA Online Journal of Language Studies, 16(2), 17-32. http://www.esptodayjournal.org/pdf

Odell, L., Goswami, D., \& Herrington, A. (1983). The discourse-based interview: A procedure for exploring the tacit knowledge of writers in nonacademic settings. In P. Mosenthal, L. Tamor, \& S. A. Walmsley (Eds.). Research on writing (pp. 221-236). New York: Longman.

Okamura, A. (2008). Citation forms in scientific texts: similarities and differences in L1 and L2 professional writing. Nordic Journal of English Studies, 7(3), 61-81. http://ub016045.ub.gu.se/ojs/index.php/njes/article/viewFile/152/150

Oskueia, M. H. H., \& Kuhi, D. (2014). The use of citations in academic writing: analysis of introduction sections of Iranian and native English master's theses. Journal of Social Issues \& Humanities, 2(3), 216-220.

Parry, S. (1998). Disciplinary differences in doctoral theses. Higher Education, 36, 273-99. doi.org/10.1023/A:1003216613001

Patton, M. Q. (1990). Qualitative evaluation and research methods. Newbury Park, CA: Sage Publications.

Petrić, B. (2007). Rhetorical functions of citations in high- and low-rated master's theses. Journal of English for Academic Purposes, 6(3), 238-253. doi:10.1016/j.jeap.2007.09.002

Petrić, B., \& Harwood, N. (2013). Task requirements, task representation, and self-reported citation functions: An exploratory study of a successful L2 student's writing. Journal of English for Academic Purposes, 12, 110-124. doi.org/10.1016/j.jeap.2013.01.002

Rabab'ah, G., \& Al-Marshadi, A. (2013). Integrative vs. non-integrative citations among native and nonnative English writers. International Education Studies, 6(7), 78-87. Retrieved from https://files.eric.ed.gov/fulltext/EJ1068542.pdf

Rowley-jolivet, E., \& Carter-thomas, S. (2014). Citation Practices of Expert French Writers of English: Issues of Attribution and Stance. A.Lyda and K. Warchal (eds.), Occupying Niches: Interculturality, Cross-culturality and Aculturality in Academic Research. Second Language Learning and Teaching. Switzerland: Springer International Publishing.

Samraj, B. (2013). Form and function of citations in discussion sections of master's theses and research articles. Journal of English for Academic Purposes, 12(4), 299-310. doi.org/10.1016/j.jeap.2013.09.001

Shi, L. (2012). Rewriting and paraphrasing source texts in second language writing. Journal of Second Language Writing, 21(2), 134-148. doi.org/10.1016/j.jslw.2012.03.003

Swales, J. M. (1990). Genre Analysis. Cambridge: Cambridge University Press.

Swales, J. M. (2013). Disciplinary identities: individuality and community in academic discourse, K. Hyland. Cambridge University Press, Cambridge (2012). Book review. Journal of Second Language Writing, 22(1), 1-3. doi.org/10.1016/j.jslw.2012.09.001

Swales, J. M. (2014). Variation in citational practice in a corpus of student biology papers: from parenthetical plonking to intertextual storytelling. Written Communication, 31(1), 118-141. doi/full/10.1177/0741088313515166

Thompson, P. (2001). A pedagogically-motivated corpus-based examination of PhD theses: macrostructure, citation practices and use of modal verbs. Unpublished thesis submitted for the degree of $\mathrm{PhD}$ to School of Linguistics and Applied Language Studies, The University of Reading, UK. Retrieved from http://citeseerx.ist.psu.edu/viewdoc/download?doi=10.1.1.119.9129\&rep=rep1\&type=pdf. 
Thompson, P. (2002). Manifesting intertextuality in the $\mathrm{PhD}$ theses. Revista Canaria De Estudios Ingleses, 44, 97-114. Retrieved from https://dialnet.unirioja.es/servlet/articulo?codigo $=300998$

Thompson, P., \& Tribble, C. (2001). Looking at citations: using corpora in English for academic purposes. Language Learning and Technology, 5(3), 91-105. https://scholarspace.manoa.hawaii.edu/bitstream/10125/44568/05_03_thompson.pdf

Yang, L. (2013). Evaluative functions of reporting evidentials in English research articles of Applied Linguistics. Open Journal of Modern Linguistics, 3(2), 119-126. doi/10.4236/ojml.2013.32016

\section{Copyrights}

Copyright for this article is retained by the author(s), with first publication rights granted to the Journal.

This is an open-access article distributed under the terms and conditions of the Creative Commons Attribution license (CC BY-NC-ND) (http://creativecommons.org/licenses/by-nc-nd/4.0/). 